\title{
Administration of paracetamol to children; do parents adhere to recommendations?
}

\author{
Wanni Arachchi TI', Gamage MWK ${ }^{1}$, Jayasinghe $\mathbf{S S}^{2}$ \\ ${ }^{\prime}$ BSc. Nursing Degree Programme, Faculty of Medicine. University of Ruhuna, Galle, Sri Lanka. \\ ${ }^{2}$ Department of Pharmacology, Faculty of Medicine, University of Ruhuna, Galle, Sri Lanka.
}

Correspondence: Ms. T I Wanni Arachchi

e-mail: thilini.ishara.ti76@gmail.com

https://orcid.org/0000-0002-6443-3871

\begin{abstract}
Introduction: Fever is a common health problem in childhood. Parents often administer paracetamol to children without consulting a doctor since it is a widely available over the counter drug. The aim of this study was to find out knowledge and practices of administration of paracetamol for children below the age of five years.

Methods: Community based descriptive cross-sectional study was carried out using a pre-tested interviewer administered questioner in Bope-Poddla Medical Officer of Health area.

Results: One hundred and six parents participated (89.6\% female). Mean age (SD) of participants was 32 (5.9) years. All parents were aware of the availability of tablets and syrup. Only 55.7\% was aware of suppositories. Majority (95.3\%) of the participants did not know the recommended dose. More than half of the parents (62.3\%) administered paracetamol without a medical advice. The association between use of package label instruction with correct dosing was statistically significant $(\mathrm{p}=0.04)$. The commonly used measuring device was a measuring cup (83\%). Among the seven teaspoon users, two knew its capacity correctly. Fifty-nine percent of the parents gave weight appropriate dose; $15.1 \%$ had given subtherapeutic dose and $25.5 \%$ given supratherapeutic dose. Level of education was not associated with correct dosing $(\mathrm{p}=0.1)$. There were statistically significant associations between the age group of the participants with correct dosing $(\mathrm{p}=0.04)$. The recommended dosing frequency was exceeded by $50.9 \%$.

Conclusions: Administration of supratherapeutic and subtherapeutic doses of paracetamol to children under five years old is not uncommon. Further, parents are not adhering to the recommended frequency of administration.
\end{abstract}

Keywords: Children, fever, knowledge, paracetamol, practice

\section{Introduction}

Fever is a common response in various childhood diseases, most commonly infections (1). Parents consider fever as a disease rather than a symptom of a disease. Hence, they often seek medical attention whenever child gets fever (2).

Parents are anxious when dealing with fever. Therefore, they immediately consult a doctor or administer an antipyretic.
Paracetamol (Acetaminophen) is a commonly used antipyretic, which is widely available as an over the counter medication (3). Most of the time, parents administer an incorrect dose of paracetamol or more frequently than recommended (4). Recent studies showed that the paracetamol toxicity in children occur following repeated supratherapeutic doses which can lead to liver impairment and death (5). 
Paracetamol is a common pharmaceutical agent involved in overdose especially among the children below six years (6). Food and Drug Administration Regulations implemented restrictions in printing dosing instructions on the package label for children less than two years, aiming to encourage parents to consult a doctor before administering. Previous studies showed that both underdose and overdose of paracetamol were administered to children due to parental errors and poor instructions by the healthcare workers (7). Further, it was identified that lack of awareness on different concentrations in various dosage forms and inability to calculate weight appropriate dose of paracetamol led to incorrect dosing of paracetamol (8).

The recommended dose of paracetamol is $10-15$ $\mathrm{mg} / \mathrm{kg}$ body weight, can go up to $75 \mathrm{mg} / \mathrm{kg}$ body weight/day, but should not exceed $100 \mathrm{mg} / \mathrm{kg}$ body weight/day as it is likely to cause hepatotoxicity. There should be at least four to six hours gap between each paracetamol dose to prevent overdosing (9).

In Sri Lanka there were few studies done to explore the dosing accuracy of caregivers. Therefore, the aim of the study was to find out knowledge and practices of administration of paracetamol to children in a selected MOH area in Galle.

\section{Methods}

A community based cross-sectional study was carried out using a pre-tested interviewer administered questionnaire after obtaining ethical clearance from the Ethics Review Committee, Faculty of Medicine, University of Ruhuna. The pretest was done in 10 randomly selected parents from Galle Municipality area. From the total 17 Public Health Midwife (PHM) areas of Bope-Poddala, $\mathrm{MOH}$ division, eight PHM areas were selected by convenient sampling method considering the feasibility to approach. Convenient sampling method was again used to select the parents from each PHM area. One hundred and six parents were recruited for the study. Single parent was interviewed from each family who had at least one child less than five years old. Informed written consent was obtained from the participants.

The questionnaire was developed based on published literature (9). It consisted of four sections to cover demographic characteristics, knowledge of parents on calculation and measuring the dose, frequency of administration, available forms etc. (16 questions), parental motives (3 questions) and practical aspect on administration (13 questions).

The association of dosing accuracy with demographic data was analyzed with Chi-square test and correlations were analyzed with Person correlation with Statistical Package of Social Science (SPSS).

\section{Results}

The majority of the participants were mothers $(89.6 \%)$. Nearly one third $(36.8 \%)$ of participants were below the age of 30 years. All participants received at least primary education (Table 1).

\section{Knowledge on paracetamol preparations and dosing}

All the participants were aware with the availability of tablets and syrup but, $75.5 \%$ knew about infant drops and only $55.7 \%$ knew about suppositories. More than half of the participants (58.5\%) knew the correct (four times per day) dosing frequency while $38.7 \%$ stated three times per day and $2.8 \%$ stated twice per day as the correct frequency.

Majority of parents $(95.3 \%)$ did not know the amount of paracetamol to be administered for one kilogram of body weight per dose and maximum dose per kilogram per day. Among the participants, $4.7 \%$ stated that the minimum dose as $5 \mathrm{mg} / \mathrm{kg}$ while $3.8 \%$ of the participants said that the maximum dose as $15 \mathrm{mg} / \mathrm{kg}$ and one parent said it was $20 \mathrm{mg} / \mathrm{kg}$.

Half of the parents incorrectly believed that the paracetamol syrup for children is more concentrated than infant drops. Among the participants, $84 \%$ of them identified poisoning can occur not only by administering a single high dose but also by giving more frequently than recommended and giving a dose more than recommended per day.

\section{Practices of use of paracetamol}

In case of fever; $13.2 \%$ of parents said that they took the child to a doctor before giving any drug including paracetamol. The sources of awareness 
of paracetamol were; from a doctor (38.6\%), media $(23.6 \%)$, pharmacist $(8.5 \%)$, friends or relatives $(12.3 \%)$ and Public Health Midwife (17\%). Fifty eight percent of parents decided the dose by using package label instructions, $36.3 \%$ with the advice of a doctor. A few parents decided the dose with directions of pharmacist or by advice of a friend who have a child with the same age.

The measuring devices used were the standard measuring cup $(83 \%)$, teaspoon $(6.6 \%)$, syringe $(4.7 \%)$ and the dropper $(5.8 \%)$. Among the respondents, only half knew the correct capacity of the teaspoon. Among the teaspoon users $(n=7)$, only two knew its capacity correctly.

In case of high fever, less than half $(45.3 \%)$ of the parents maintained correct (six hour) time gap between two doses and 3.8\% said they maintained eight hours gap. The rest (50.9\%) administered paracetamol without waiting for six hours from the last dose. Among them, 27.4\% maintained four hours gap and $20.8 \%$ maintained five hours gap and one of the participants said that he maintained three hours gap.
Dose of paracetamol administered by $59.4 \%$ of the respondents was weight appropriate $(10 \mathrm{mg} /$ $\mathrm{kg} /$ dose- $15 \mathrm{mg} / \mathrm{kg} /$ dose) while $15.1 \%$ had given subtherapeutic dose $(<10 \mathrm{mg} / \mathrm{kg} / \mathrm{dose})$ and $25.5 \%$ had given supratherapeutic dose ( $>15 \mathrm{mg} / \mathrm{kg} / \mathrm{dose})$. The maximum dose administered was $35.21 \mathrm{mg} / \mathrm{kg}$.

\section{Association of use of paracetamol with demographic data}

There were statistically significant associations between the use of package label instruction and correct dosing $(\mathrm{p}=0.04)$, parents age (above 30 years) and correct dosing $(\mathrm{p}=0.04)$ (Table 2$)$. There was no association between dosing accuracy with level of education or knowledge of side effects.

There were statistically significant associations between the level of education and the dosage decided on doctor's advice $(p=0.02)$ and between level of education and dose decision according to package label $(p=0.02)$ (Table 2). There were no correlations between correct dosing and age of the parent or the number of children in the family.

Table 1: Baseline characteristics

\begin{tabular}{lll}
\hline Characteristics & & \% \\
\hline \multirow{2}{*}{ Age (years) } & $<30$ & 36.8 \\
& $>30$ & 63.2 \\
\hline \multirow{2}{*}{ Gender } & Female & 89.6 \\
& Male & 10.4 \\
\hline \multirow{2}{*}{ Marital status } & Married & 98.1 \\
& Separated & 0.9 \\
\hline \multirow{3}{*}{ Educational status } & Primary education & 12 \\
& O / L & 35 \\
& A / L & 43 \\
& Degree / Diploma & 10 \\
Number of children & One & 38.7 \\
& Two & 44.3 \\
& More than two & 17 \\
\hline
\end{tabular}


Table 2: Associated factors with dosing accuracy

\begin{tabular}{|c|c|c|c|}
\hline \multirow{2}{*}{ Variable } & \multicolumn{2}{|c|}{ Number of participants (\%) } & \multirow{2}{*}{ P value } \\
\hline & Correct dose & Incorrect dose & \\
\hline \multicolumn{4}{|l|}{ Age } \\
\hline$<30$ years & $28(44.4)$ & $11(25.6)$ & \multirow[b]{2}{*}{0.04} \\
\hline$>30$ years & $35(55.6)$ & $32(74.4)$ & \\
\hline \multicolumn{4}{|l|}{ Educational level } \\
\hline Primary education & $5(7.6)$ & $8(18.6)$ & \multirow{4}{*}{0.06} \\
\hline Up to $\mathrm{O} / \mathrm{L}$ & $18(28.6)$ & $19(44.2)$ & \\
\hline $\mathrm{Up}$ to $\mathrm{A} / \mathrm{L}$ & $32(50.8)$ & $13(30.2)$ & \\
\hline Degree/Diploma & $8(12.7)$ & $3(7)$ & \\
\hline \multicolumn{4}{|l|}{ Gender } \\
\hline Female & $59(93.7)$ & $36(83.7)$ & \multirow[b]{2}{*}{0.1} \\
\hline Male & $4(6.3)$ & $7(16.3)$ & \\
\hline \multicolumn{4}{|c|}{ Dose deciding on doctor's advice } \\
\hline Yes & $25(39.7)$ & $22(51.2)$ & \multirow[b]{2}{*}{0.2} \\
\hline No & $38(60.3)$ & $21(48.8)$ & \\
\hline \multicolumn{4}{|c|}{ Dose deciding on package label instructions } \\
\hline Yes & $47(74.6)$ & $24(55.8)$ & \multirow[b]{2}{*}{0.04} \\
\hline No & $16(25.4)$ & $19(44.2)$ & \\
\hline \multicolumn{4}{|c|}{ Dose deciding on pharmacist advice } \\
\hline Yes & $1(1.6)$ & $4(9.3)$ & \multirow[b]{2}{*}{0.07} \\
\hline No & $62(98.4)$ & 39 (90.7) & \\
\hline
\end{tabular}

\section{Discussion}

Paracetamol is an over the counter drug which is commonly used to relieve pain and fever. As it is a drug common to cause toxicity, it is important to emphasize the value of taking the correct dose, especially when administering to children as overdose can damage liver and kidney.

The current study explored the knowledge and practices of administration of paracetamol to children. Confirming with the available literature, most of the parents incorrectly believed that children's paracetamol syrup is more concentrated than infant drops $(3,9)$ which can lead to either overdose or underdose. Further, the situation is complicated with the availability of number of brands with varying concentrations.
This study highlights inadequate knowledge on the calculation of dose of paracetamol as only $5 \%$ knew the weight appropriate dose. The finding is parallel with the results of Ramanayake $\mathrm{R} P$ et al. (2012), in which only one participant could calculate the dose correctly (9). They found that $11 \%$ of caregivers had given subtherapeutic dose $(<10 \mathrm{mg} / \mathrm{kg} / \mathrm{dose})$ while $43 \%$ had given a supra therapeutic dose $(>15 \mathrm{mg} / \mathrm{kg} / \mathrm{dose})$ for children. Surprisingly, $6 \%$ of caregivers altered the dose based on the severity of fever. Further, $16 \%$ administered more frequently than recommended (9).

Bilenco N, et al. (2006) showed that administration of supratherapeutic dose of antipyretics is common which was $34.8 \%$ according to their results (10). 
In Sri Lanka it was shown that administration of supratherapeutic dose was $43 \%$ in 2012 (9). The current study showed the lowest figure that is $25.5 \%$. This clear reduction of administration of supratherapeutic dose may be due to proper instructions by doctors, pharmacists and health care workers, clear instructions on paracetamol package label / leaflet or education through mass media regarding the toxicity.

According to Ramanayake R P, et al. (2012) $80 \%$ of the parents maintained six hours gap between two doses (9). In the current study around $70 \%$ of the parents maintained $4-6$ hours gap between two doses. However Bilenco N, at el (2006) showed one fifth of the parents repeated the dose at intervals less or equal to three hours.

In spite of advice from doctors and package label instructions on dose of paracetamol, parents administer supratherapeutic or subtherapeutic dose of paracetamol and also more frequently than recommended. According to Obu HA, at el (2012) most care givers relied on past experience (71.2\%) rather than on enclosed information leaflet to decide the appropriate dose (11). It is obvious that accurate dosing and frequency is a must to get desired outcome while avoiding the toxicity. Thus, health care workers should guide and emphasize parents on administration of correct dose of paracetamol to children without assuming that they know the facts. Further, printing of dose instruction on the package label in a large font, displaying calculation of weight appropriate dose in pharmacies, well baby clinics and pediatric clinics might help to improve safe and effective administration of paracetamol.

\section{References}

1. Dipak J Kanabar. A Practical Approach to the Treatment of Low Risk Childhood Fever. Drugs, 2014; 14: 45-55.

2. Crocetti M, Moghbeli N, Serwint J. Fever phobia revisited: have parental misconceptions about fever changed in 20 years? Pediatrics, 2001 Jun; 107(6): 1241-6.
3. Janne FT, Louise LT, Margareta S, Hanne T, Volkert S. Paracetamol for feverish children: parental motives and experiences. Scandinavian Journal of Primary Health Care: 2010; 28: 115-20.

4. Maurizio De Martino, Alberto Chiarugi. Recent advances in pediatric use of oral paracetamol in fever and pain management. Pain Therapy, 2015; 4: 149-68.

5. Kelly L. Hayward, Elizabeth E. Powell, Katharine M. Irvine, Jennifer H. Martin. Can Paracetamol (acetaminophen) be administered to patients with liver impairment?. Be J Coin Pharmacology. October 2015; 81(2): 210-22.

6. Herbert A Obu, Joseph at M Chinawa, Agozie C Ubesie, Christopher B Eke, Ikenna K Ndu. Paracetamol use (ad / or misuse) in children in Enugu, South- East, Nigeria. BMC Pediatrics, 2012;12: 103.

7. Barrett TW, Norton VC. Parental knowledge of different acetaminophen concentrations for infants and children. Academic Emergency Medicine, 2008; 7(6): 718-21.

8. Dipak J Kanabar. A clinical and safety review of paracetamol and ibuprofen in children. Inflammopharmcology, 2017; 25: 1-9.

9. Ramanayake R P, Jayasinghe L R, De Silva A H, Wijesinghe W A, Kanaganayagam N. Knowledge and practices of paracetamol administration among caregivers of pediatric age group patients. J Family Med Prim Care, 2012 Jan; 1(1): 30-3.

10. Bilenco N, Tessier H, Okbe R, Press J, Gorodischer R.Determinantsof antipyretic misuse in children up to 5 years of age: a cross-sectional study. Clinical Therapeutics. 2006 May; 28(5): 783-93.

11. Obu HA, Chinawa JM, Ubesie AC, Ake CB, Ndu LK. Parcetamol use (and / or misuse) in children in Enugu, South- East, Niria. BMC Pediatrics, 2012 July; 19: 12103. 